\title{
Consentimento livre e esclarecido: ainda uma ferramenta útil na ética em pesquisa
}

\author{
DOI: $10.3395 /$ reciis.v2.Sup1.208pt
}

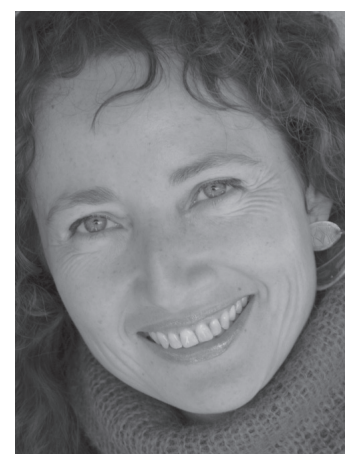

Florencia Luna

Faculdade Latinoamericana de Ciencias Sociais e Universidade de Buenos Aires, Buenos Aires, Argentina

florluna@pccp.com.ar

\section{Resumo}

Este artigo discute o termo de consentimento livre e esclarecido (TCLE): sua evolução, seus principais desafios e seus pressupostos teóricos. Esse processo passa pela inter-relação do TCLE com a história, com a evolução da ética em pesquisa e com os abusos cometidos em estudos biomédicos. $\mathrm{O}$ artigo apresenta as objeções feitas ao TCLE, em especial as que surgem com relação a sua implementação nos países em desenvolvimento. Aborda também os problemas de natureza epistemológica e aqueles relacionados à capacidade de ação, dadas as condições contextuais em que o TCLE é obtido. Expõe, ainda, a justificativa tradicional do TCLE como oferecida pelo Relatório Belmont, bem como uma freqüente simplificação dessa justificativa, enfocando apenas o aspecto deliberativo do TCLE, em que a ênfase na autonomia ou na deliberação supõe uma visão inapropriada dos sujeitos de pesquisa.

\section{Palavras-chave}

termo de consentimento livre e esclarecido (TCLE); termo de assentimento; consentimento voluntário; livre direito de escolha; autonomia; países em desenvolvimento

\section{Introdução}

O termo de consentimento livre e esclarecido (TCLE) foi um dos primeiros recursos da ética em pesquisa e, em certo sentido, pode ser considerado emblemático. A história da ética em pesquisa está profundamente relacionada ao TCLE. Quando as primeiras questões sobre esse assunto começaram a ser consideradas, parecia que quase todos os problemas apresentados pela investigação abusiva poderiam ser resolvidos se um bom TCLE fosse obtido.
Os primeiros casos que revelaram a importância do TCLE na ética em pesquisa foram os abusos cometidos durante a Segunda Guerra Mundial. Médicos obrigavam pessoas a beber água salgada a fim de descobrir quanto tempo um ser humano poderia sobreviver sem água potável. Em Dachau, presos eram imersos em águas geladas para que se pudesse descobrir quanto tempo um piloto poderia viver se o seu avião fosse derrubado no Canal Inglês, bem como que tipos de equipamentos de proteção ou técnicas de reaquecimento seriam mais eficazes. Autoridades militares nazistas estavam preocupadas com 
doenças que as tropas alemãs poderiam contrair na África ou na Europa Oriental, e os médicos nos campos usavam os "materiais humanos" à sua disposição para desenvolver medicamentos. Centenas de pessoas morreram nesses experimentos; muitos daqueles que sobreviveram tiveram que viver com dolorosas cicatrizes, físicas ou psicológicas (Annas \& Grodin 1992).

Esses experimentos foram perpetrados pelos nazistas durante a guerra. A Alemanha naquela época era altamente avançada cientificamente, e essas experiências foram conduzidas por médicos-pesquisadores alemães (Annas \& Grodin 1992). ${ }^{1}$ Elas representam aberrações no campo da pesquisa não-terapêutica. Uma das questões a serem consideradas sobre essas situações é que os sujeitos de pesquisa eram prisioneiros de guerra em condição de total subordinação, sem qualquer chance de consentimento (Luna 2007).

Esse tipo de abuso posteriormente levou à elaboração do Código de Nurembergue. Embora não seja o primeiro documento na área de ética em pesquisa, ele é paradigmático e um dos documentos mais bem conhecidos. Sua intenção era a de eliminar a pesquisa antiética, e o foco adotado foi sobre o TCLE. De fato, o artigo primeiro é relativo ao TCLE, cuja exigência é tão elevada que apenas adultos com capacidade legal poderiam consentir. O artigo primeiro (1947) estabelece:

O consentimento voluntário do sujeito humano é absolutamente essencial. Isso significa que as pessoas que serão submetidas ao experimento devem ser legalmente capazes de dar consentimento; devem exercer o livre direito de escolha sem qualquer intervenção de elementos de força, fraude, mentira, coação, astúcia ou outra forma de restrição posterior; e devem ter conhecimento e compreensão suficiente do assunto em estudo para tomar uma decisão informada e esclarecida. Esse último aspecto exige que, antes de se receber uma resposta afirmativa das pessoas à sua inclusão no experimento, lhes sejam explicados a natureza, a duração e o propósito do experimento; os métodos e meios pelos quais será conduzido; as inconveniências e os riscos esperados; e os efeitos sobre a saúde ou sobre a pessoa do participante que eventualmente possam ocorrer devido à participação no experimento. $\mathrm{O}$ dever e a responsabilidade de garantir a qualidade do consentimento repousam sobre cada indivíduo que inicia ou dirige um experimento, ou que se compromete com ele. São deveres e responsabilidades pessoais que não podem ser delegados a outrem impunemente.

Esse é, sem dúvida, um artigo forte e claro que afirma a importância do TCLE e estabelece os principais elementos que devem estar presentes. No entanto, o Código de Nurembergue não foi suficiente para impedir pesquisas abusivas posteriores. Infelizmente, abusos em investigações também foram cometidos em tempos de paz e prosperidade. Esses casos ocorreram durante a chamada "era de ouro da pesquisa" nos Estados Unidos. Essa era uma época em que a vida parecia ser aprimorada pelo "progresso" e em que doenças e enfermidades viriam a ser interrompidas pela boa ciência. Havia uma espécie de fé na ciência e no progresso, e a humanidade parecia estar chegando a uma era de conforto e bem-estar. Mas nem tudo era dourado e, mesmo naquela época, casos abusivos foram revelados. Quando se analisam esses casos, pode-se entender por que o TCLE parecia ser a resposta ou, pelo menos, uma resposta muito importante para evitar futuros casos similares.

Um caso infame foi o experimento Tuskegee, que durou 40 anos, de 1932 até 1972 . O experimento buscava investigar o processo natural da sífilis em homens negros, de escassos recursos, no Alabama, sul dos Estados Unidos. O estudo foi realizado pelo Serviço de Saúde Pública dos Estados Unidos. Os sujeitos da pesquisa acreditavam estar recebendo tratamento, quando, na verdade, estavam apenas recebendo alguns preparos medicinais. $\mathrm{O}$ experimento começou em um momento em que não havia tratamento eficaz para a sífilis, mas continuou por décadas depois de a penicilina ser descoberta e de a doença ser efetivamente controlada. Nesse caso, não houve TCLE. Os participantes foram intencionalmente ludibriados.

O estudo sobre imunidade ao câncer foi outro caso importante. Nesse experimento, células cancerosas vivas foram injetadas em vinte e dois sujeitos humanos. Isso foi feito em um período em que a palavra "câncer" era sinônimo de morte. De acordo com uma análise recente, os participantes, que também se encontravam na condição de pacientes hospitalizados, foram "meramente avisados de que receberiam 'algumas células' - a palavra câncer foi totalmente omitida” (Rothman 1991: 74-75). Com base nesse caso, pode-se mais uma vez constatar como há problemas com o TCLE. Nesse experimento, os pesquisadores retiveram informações importantes sobre o estudo, comprometendo a qualidade das informações a serem oferecidas nesse processo. Um aspecto interessante a ser destacado com relação a esse caso é que os investigadores tinham a "intuição" correta, e efetivamente o câncer não foi transmitido por meio das injeções. Nesse sentido, pode-se dizer que os participantes não foram “prejudicados" pelo experimento. No entanto, a ilusão presente no processo de consentimento e recrutamento denuncia as injustiças feitas aos participantes.

Um outro caso descrito na literatura também evidencia problemas com o TCLE. Nesse caso, realizou-se a indução artificial da hepatite em uma instituição para crianças com problemas mentais, na qual uma forma leve da doença era endêmica (Rothman 1991). O TCLE foi solicitado aos pais das crianças, mas a única forma de terem seus filhos aceitos na instituição - um recurso bastante escasso na época - era aceitar que eles fossem incluídos nessa pesquisa. Novamente, a "coerção sutil" atrapalhava o processo de consentimento.

Todos esses casos arriscaram a vida e a saúde das pessoas sem seu consentimento ou aprovação (Rothman 1991). ${ }^{2}$ Muitos deles foram apresentados pelo anestesiologista Henry Beecher (1966) em um artigo publicado no New England Journal of Medicine. Infelizmente, esses casos não representam apenas alguns raros exemplos, mas descrevem como os principais investigadores no período entre 1945 e 1965 agiram arbitrariamente (Rothman 1991). ${ }^{3}$ Isso dizia respeito a pesquisa terapêutica, popu- 
lações isoladas ou indivíduos com educação deficiente. Todos os casos apresentados expressam um problema característico da bioética incipiente: o respeito insuficiente à autonomia dos participantes de pesquisa. Nesse sentido, a solução foi novamente a de fortalecer o TCLE como uma ferramenta para evitar pesquisas abusivas.

Este artigo discute o termo de consentimento livre e esclarecido (TCLE): sua evolução, seus principais desafios e seus pressupostos teóricos. Esse processo passa pela inter-relação do TCLE com a história, com a evolução da ética em pesquisa e com os abusos cometidos em estudos biomédicos. O artigo apresenta as objeções feitas ao TCLE, em especial as que surgem com relação a sua implementação nos países em desenvolvimento. Aborda também os problemas de natureza epistemológica e aqueles relacionados à capacidade de ação, dadas as condições contextuais em que o TCLE é obtido. Expõe, ainda, a justificativa tradicional do TCLE como oferecida pelo Relatório Belmont, bem como uma freqüente simplificação dessa justificativa, enfocando apenas o aspecto deliberativo do TCLE, em que a ênfase na autonomia ou na deliberação supõe uma visão inapropriada dos sujeitos de pesquisa.

\section{A Declaração de Helsinque e as Diretrizes do Conselho de Organizações Internacionais de Ciências Médicas/ Organização Mundial da Saúde}

Uma questão a considerar é por que o Código de Nurembergue não foi bom o suficiente e não ajudou a evitar os casos abusivos durante a era de ouro da pesquisa. Parte da resposta é que a pesquisa na era de ouro era principalmente terapêutica, e não só não-terapêutica, como nos tempos de guerra. Afirma-se também que os pesquisadores sentiram que o Código de Nurembergue não se aplicava a eles, que eram investigadores, não "nazistas”. Finalmente, os pesquisadores também chamaram a atenção para o fato de que a exigência do TCLE no Código de Nurembergue era muito forte e formal; o código era um documento redigido por advogados, sendo necessário, portanto, outro tipo de documento.

Devido a essas razões, a Declaração de Helsinque surgiu como um documento feito por médicos e para médicos. Mas nota-se, na declaração, que a situação do TCLE mudou e que existem outros mecanismos de proteção além dele. Por exemplo, a pesquisa biomédica envolvendo sujeitos humanos deve ser conduzida apenas por pessoas cientificamente qualificadas e sob a supervisão de um médico clinicamente competente. Deve, também, respeitar princípios científicos já aceitos. A declaração indica, ainda, que a responsabilidade pelo participante humano deve sempre estar nas mãos de um profissional médico qualificado, e nunca nas mãos do próprio sujeito, ainda que ele tenha dado seu consentimento. Os artigos sobre o TCLE aparecem na última parte da Seção I da Declaração de Helsinque, onde são apresentados os princípios básicos. Os artigos I. 9 e I. 10 estabelecem (World Medical Organization 1996):
I. 9. Em qualquer pesquisa envolvendo seres humanos, cada participante em potencial deve ser adequadamente informado quanto aos objetivos, métodos, benefícios previstos e potenciais danos do estudo, e o incômodo que este possa acarretar. Deve ser informado de que tem plena liberdade para se abster de participar do estudo e de que é livre para retirar seu consentimento em participar a qualquer momento. O médico deve então obter o consentimento informado livremente dado pelo participante, de preferência por escrito.

I. 10. Ao obter o consentimento informado, o médico deve ser particularmente cauteloso se o sujeito tiver relação de dependência a ele e possa consentir sob coação. Nesse caso, o consentimento informado deve ser obtido por um médico que não esteja envolvido na pesquisa e que seja completamente independente desse relacionamento oficial.

Diferentemente do Código de Nurembergue, a Declaração de Helsinque permite a pesquisa em pessoas sem competência legal. O artigo I. 11 determina (World Medical Organization 1996):

I. 1 1. Em caso de incompetência legal, o consentimento informado deve ser dado pelo guardião legal, em conformidade com a legislação nacional. Quando uma incapacidade física ou mental impossibilita a obtenção do consentimento informado, ou quando o participante for menor de idade, a permissão do familiar responsável substitui a do participante, obedecendo-se à legislação nacional. Sempre que o menor for de fato capaz de dar seu consentimento, este deve ser obtido, além daquele de seu guardião legal.

$\mathrm{Na}$ Seção II, que trata da pesquisa clínica (investigação médica combinada com cuidados profissionais), a Declaração de Helsinque permite a pesquisa sem TCLE em certos casos (World Medical Organization 1996):

II. 5. Se o médico considera essencial não obter o consentimento informado, as razões específicas para essa proposta devem ser declaradas no protocolo experimental a ser transmitido ao comitê independente $(1,2) .5$

Assim, a Declaração de Helsinque foi mais ampla do que o Código de Nurembergue e permitiu investigações que o código não autorizava. Ela centrou-se não apenas nas pesquisas não-terapêuticas, mas também naquelas que poderiam beneficiar os participantes. A Declaração de Helsinque, por conseguinte, estabeleceu o padrão tanto do TCLE como de procedimentos aceitos em uma pesquisa ética.

As Diretrizes Éticas Internacionais para Pesquisas Biomédicas Envolvendo Seres Humanos, também conhecidas como Diretrizes do CIOMS (Conselho de Organizações Internacionais de Ciências Médicas) e da OMS (Organização Mundial da Saúde), foram elaboradas em 1993, e sua intenção inicial era complementar a Declaração de Helsinque. Em conseqüência, pode-se encontrar nesse documento o mesmo espírito da declaração. Por exemplo, na diretriz 4, que discute o consentimento livre e esclarecido individual, ou na diretriz 9, que abrange os casos de limitações especiais sobre risco quando a pesquisa envolve pessoas que não são capazes de dar seu consentimento, são apresentadas as mesmas 
idéias da Declaração de Helsinque e até mesmo algumas outras especificações.

É possível também se deparar com diretrizes que complementam a Declaração de Helsinque - por exemplo, a diretriz 5, que detalha as informações essenciais a serem dadas a participantes em potencial: a) as razões pelas quais a pessoa é considerada adequada para a investigação e o fato de que a participação é voluntária; b) que o indivíduo é livre para se recusar a participar e para se retirar da investigação a qualquer momento, sem penalidade ou perda de benefícios aos quais ele teria direito; c) a finalidade da investigação, os procedimentos a serem realizados pelo pesquisador e pelo participante e uma explicação de como a investigação difere dos cuidados médicos de rotina; d) para ensaios controlados, uma apresentação das características do delineamento da pesquisa (por exemplo, randomização, duplo-cego) e a explicação de que o participante não será avisado do tratamento designado até que o estudo seja concluído e essa informação possa ser revelada; e) a duração prevista da participação, incluindo o número e a duração das visitas ao centro de pesquisa e o tempo total envolvido, bem como a possibilidade de término antecipado do ensaio ou da participação do indivíduo; f) quaisquer riscos, dor ou desconforto previsíveis, ou inconveniências para o indivíduo (ou outros) associados à participação na pesquisa, incluindo riscos à saúde ou ao bem-estar do cônjuge ou companheiro do sujeito. Os pontos acima mencionados são apenas seis entre vinte outros que essa diretriz apresenta.

No documento do CIOMS/OMS, também existem diretrizes concernentes às obrigações dos patrocinadores e pesquisadores em relação às maneiras adequadas de obter consentimento, como a diretriz 6 ou as que abrangem populações vulneráveis. Por exemplo, a diretriz 13 estabelece que uma justificativa especial é exigida para convidar indivíduos vulneráveis a serem participantes de pesquisa e que, se eles forem selecionados, os meios de proteção dos seus direitos e do seu bem-estar devem ser rigorosamente aplicados.

Em pesquisas envolvendo crianças, a diretriz 14 especifica uma série de condições. Exige que, antes de conduzi-las, o investigador deve assegurar que: o experimento não possa ser igualmente realizado com adultos; o objetivo da pesquisa seja obter conhecimentos relevantes para as necessidades de saúde de crianças; um dos pais ou o representante legal de cada criança tenha dado autorização; a concordância (assentimento) de cada criança tenha sido obtida na medida de sua capacidade; e que a recusa por parte da criança em participar ou continuar na investigação será respeitada. Dessa forma, mesmo que a pesquisa em crianças seja permitida, esse documento estabelece explícitos mecanismos de proteção a serem considerados. Nessa mesma linha, a diretriz 15 é especificamente dedicada à pesquisa envolvendo indivíduos que, por causa de transtornos mentais ou comportamentais, não são capazes de dar o seu consentimento livre e esclarecido adequadamente. Ela estabelece as condições que devem ser cumpridas a fim de fazer pesquisas com essa população.
Ambos os documentos, a Declaração de Helsinque e as Diretrizes do CIOMS/OMS, foram revisados subseqüentemente, mas as mudanças foram pouco significativas até 2000. Infelizmente, a Declaração de Helsinque de 2000, com suas notas de esclarecimento, e as Diretrizes do CIOMS/OMS de 2002 divergem em suas últimas versões, mas isso faz parte de outra história da ética em pesquisa (Luna 2007).

Quando se analisam os casos abusivos descritos inicialmente, descobre-se que a maioria dos problemas neles presentes estava relacionada a um processo inadequado de consentimento livre e esclarecido. Como se pode inferir do primeiro artigo do Código de Nurembergue até o documento do CIOMS/OMS, houve uma evolução e sofisticação desse processo, e o TCLE foi estabelecido como um elemento necessário das investigações. Nesse ponto da ética em pesquisa, parecia que quase todos os problemas poderiam ser resolvidos por meio de um bom TCLE: com informações claras e precisas, sem enganos e sem coerção indevida. Isso tudo parecia ser a resposta.

\section{Os países em desenvolvimento apresentam problemas especiais?}

O TCLE é um processo bastante complexo. Não se trata apenas de um formulário que deve ser assinado, ainda que muitos pesquisadores pensem dessa forma. Embora tenha sido criado como uma "regra de ouro" no domínio da ética em pesquisa, o TCLE ainda hoje enfrenta muitos problemas em sua implementação. Por exemplo, uma questão é a grande quantidade de informação que ele tem de fornecer. Note-se que, ao se abordar a diretriz 5 do documento do CIOMS/OMS, foram mencionados apenas seis pontos dentre os vinte e seis listados pela diretriz. Mesmo que se reconheça a importância de dar cada uma dessas informações a um possível participante de pesquisa, é muito difícil conseguir isso de forma simples e compreensível. Problemas relacionados à extensão dos formulários de consentimento livre e esclarecido, à sofisticação de algumas informações a serem fornecidas, à capacidade de compreender, entre outros, são difíceis de evitar e constituem um desafio para um bom processo de consentimento.

Além dessas objeções gerais, ultimamente várias críticas têm surgido em relação ao TCLE nos países em desenvolvimento. Alega-se que o TCLE é demasiado formal, que é insensível a certas condições, que é uma exigência excessivamente rígida quando os riscos são pequenos, e que é bastante difícil compreender ou transmitir suas informações. Por exemplo, o relatório sobre uma consulta internacional afirmou: "Freqüentemente, o consentimento livre e esclarecido é uma comunicação única e unidirecional, um obstáculo que os pesquisadores precisam transpor para irem para a etapa seguinte do seu protocolo de pesquisa" (Heise \& Wood 2005: 19).

Quais são as condições que podem dificultar o TCLE em países em desenvolvimento? As palavras lidas nos artigos sobre esses países são muito semelhantes: "[Eles são] socioculturalmente diversificados em termos de língua, religião, economia e tradição. Uma grande per- 
centagem da população é altamente vulnerável devido às desigualdades estruturais, ao racismo, à pobreza, à baixa alfabetização e à disparidade de gênero" (Bhan et al. 2006: 39). ${ }^{4}$

O significado dessas palavras para vários países em desenvolvimento pode ser muito diferente. No entanto, elas podem ser corretamente aplicadas à Nigéria, à Guatemala, ao Malawi ou à Índia, apesar de a diversidade, a língua, a tradição ou a religião poderem ser marcadamente distintas em cada um. Existem formas em que essas diferenças possam afetar o processo de consentimento livre e esclarecido?

Neste momento, cabe analisar se essas críticas são válidas, se o TCLE nos países em desenvolvimento é uma estratégia inútil. Para tanto, serão apresentadas algumas estratégias que podem ser seguidas a fim de proteger os sujeitos de pesquisa de maneira adequada. Também é importante chamar a atenção para dois diferentes aspectos do TCLE: o primeiro tem a ver com condições epistemológicas, isto é, com a capacidade de compreender informações adequadamente; e o segundo tem a ver com a ação, a liberdade e a capacidade de ser verdadeiramente voluntário. Esse último ponto está relacionado às condições contextuais em que o TCLE é dado. Essas condições podem limitar a capacidade de ação dos indivíduos e são mais prováveis de aparecer em situações de escassez de recursos e de extrema necessidade, como, por exemplo, em ambientes de pesquisa comumente encontrados em países em desenvolvimento. A diferença de natureza desses dois aspectos do TCLE aponta para diversos tipos de problema. Enquanto o primeiro pode encontrar soluções relativamente boas, o segundo pode revelar-se mais difícil de resolver.

\section{A qualidade do TCLE em países em desenvolvimento}

Freqüentemente, supõe-se que a qualidade do TCLE na pesquisa clínica nos países em desenvolvimento é deficiente, ou pior do que nos países desenvolvidos. Parte do raciocínio tem a ver com a seguinte citação: "Os participantes são analfabetos, não estão familiarizados com a pesquisa biomédica e com o TCLE e têm acesso limitado a serviços de saúde" (Levine 1998; Resnik 1998; Alvarez Castillo 2002).

Esse é o pressuposto que Christine Pace, Christine Grady e Ezequiel Emanuel levaram em consideração em um texto preliminar. ${ }^{5}$ A fim de analisar se a hipótese era verdadeira, eles compararam dados provenientes de países desenvolvidos e de países em desenvolvimento encontrados na base de dados PubMed de 1996 a 2002. Eles selecionaram estudos que: a) utilizavam métodos quantitativos; b) pesquisavam participantes ou pais de participantes pediátricos em ensaios reais; c) não testavam intervenções específicas para obtenção de consentimento; e d) avaliavam pelo menos um dos domínios de compreensão, motivações e voluntariedade. Os autores encontraram quatro estudos de países em desenvolvimento e dezesseis de países desenvolvidos que obedeciam a esses critérios. Eles informaram que os estudos de ambos os ambientes apresentavam a variável compreensão, em particular a respeito de efeitos colaterais e randomização. A expectativa de benefícios à saúde foi um dos principais motivos para a participação entre mais da metade dos sujeitos no Estudo de Gâmbia e em quatro estudos de países desenvolvidos. 52\% dos participantes em Bangladesh e de 20\% a 45\% dos sujeitos em seis estudos de países desenvolvidos não sabiam que poderiam se retirar do ensaio clínico.

Numa primeira e preliminar versão desse estudo, os autores reconheceram a necessidade de pesquisas sistemáticas mais rigorosas na área, mas concluíram que os dados não comprovavam as afirmações de que a qualidade do TCLE é pior em países em desenvolvimento. No entanto, na versão publicada, eles focalizaram a escassez de dados, bem como a dificuldade de comparar os dados dos diferentes ensaios clínicos, assumindo uma posição cautelosa. Eles afirmaram que: "Há, de fato, sinais que alertam para a compreensão dos participantes e para o questionamento de se eles estão agindo voluntariamente, mas, ao contrário de algumas alegações, esses alertas parecem aplicar-se tanto aos países desenvolvidos quanto aos em desenvolvimento" (Pace et al. 2003).

\section{O ponto de vista dos investigadores}

Existe algum posicionamento diferente na opinião dos pesquisadores de países em desenvolvimento? Hyder e Wali (2006) publicaram um artigo sobre a opinião de pesquisadores desses países em relação ao TCLE. Esse trabalho é um dos poucos estudos empíricos sobre o TCLE em países em desenvolvimento. O artigo diz que há uma avaliação geral positiva sobre como o TCLE é obtido nessas nações. Destaca que os pesquisadores estão "bem conscientes da importância do consentimento na pesquisa em saúde" (Hyder \& Wali 2006: 31). Os autores também ressaltam a necessidade de educar adequadamente a comunidade-alvo: "Tornar o conceito do projeto de pesquisa compreensível foi visto como crucial, assim como levar em conta o tempo adequado para a educação antes do recrutamento" (Hyder \& Wali 2006: 37). Assinala-se, ainda, que pesquisadores de países em desenvolvimento "acreditam fortemente no princípio do TCLE” (Hyder \& Wali 2006:40).

Um estilo diferente de artigo sobre o TCLE em um país emergente e dois países em desenvolvimento foi publicado na Medical Ethics (Bhan et al. 2006). Esse artigo apresenta exemplos da Índia, do Irã e da Nigéria. Os autores ressaltam a diversidade dentro e entre situações de países emergentes e em desenvolvimento. Mas, no final, enfatizam a importância do TCLE na pesquisa e na prática clínica, salientando também a necessidade de ser criativo e inovador em sua obtenção. Curiosamente, esses autores, oriundos de países em desenvolvimento bastante diferentes, também endossam o TCLE.

Assim, os pontos de vista desses artigos apóiam a utilidade do TCLE. No entanto, Hyder e Wali (2006) relataram algumas questões problemáticas. Eles observaram que: a) o consentimento escrito não era utilizado por quase $40 \%$ dos pesquisadores em seus estudos mais 
recentes; b) uma grande proporção recomendava mais flexibilidade nas formas de documentar o TCLE; e c) $84 \%$ dos pesquisadores concordavam que um mecanismo para medir a compreensão deveria ser incorporado.

Note-se que alguns dos problemas mencionados se referem, de uma forma ou de outra, às condições epistemológicas do TCLE, ou seja, à capacidade de compreender adequadamente as informações. $\mathrm{O}$ analfabetismo pode ser considerado uma condição epistemológica paradigmática. Ele envolve a possibilidade de pessoas sem educação formal entenderem informações sofisticadas e por vezes escritas. Outra questão relacionada ao fator epistemológico no processo de consentimento é sua "documentação", no sentido de contribuir para se certificar de que a compreensão seja alcançada.

Quanto ao primeiro ponto apresentado por Hyder e Wali, acredita-se que a proporção de $40 \%$ de pesquisadores sem utilizar o consentimento livre e esclarecido escrito parece demasiado elevada, merecendo uma explicação minuciosa que não está disponibilizada. Apesar de existirem comentários a respeito do consentimento da comunidade, a não-utilização do TCLE escrito não é uma questão secundária. O TCLE não pode ser simplesmente substituído pelo "consentimento dos líderes", como partes do artigo parecem sugerir. Atitudes como as que Vargas-Parada et al. (2006) apresentam sobre investigações no México são preocupantes. Esse estudo relata que "a maioria dos pesquisadores permitia ao paciente apenas alguns minutos para tomar uma decisão [...]" e refere-se a uma pesquisa brasileira com resultados semelhantes (Vargas-Parada et al. 2006: 41). O fato de não haver nenhuma assinatura ou formulários para distribuição é uma coisa; ignorar o TCLE ou negligenciá-lo é outra.

É verdade que um formulário escrito ou uma assinatura em culturas orais não têm significado real. Deveria haver, no entanto, maneiras claras e plausíveis de se dar provas de que o processo de consentimento foi conduzido adequadamente, como por meio de filmagem ou da presença de advogados dos pacientes durante o processo. O analfabetismo não é desculpa. Esse tipo de problema está relacionado ao aspecto epistemológico do TCLE, que incide sobre a capacidade de compreensão. Mas o fato de um sujeito de pesquisa ser analfabeto não é um obstáculo intransponível. $\mathrm{O}$ analfabetismo não pode ser considerado uma deficiência cognitiva. É uma eventualidade relacionada à ausência de uma tradição escrita em determinada cultura, ou à falta de acesso a essa tradição. Nada disso são deficiências insuperáveis na capacidade de compreender informações complexas. Cuidados devem ser tomados para evitar concepções equivocadas sobre pessoas analfabetas (Luna 2006). No caso específico do TCLE, isso pode ser resolvido oferecendo-se maior número de sessões, assistentes sociais que falem a língua dessas pessoas, recursos audiovisuais, entre outras alternativas.

Fitzgerald et al. (2003) publicaram um estudo no periódico The Lancet onde foram analisadas duas formas de conduzir o processo de consentimento em uma pes- quisa sobre a transmissão do HIV para identificar fatores de resistência dos hospedeiros ao HIV-1 em pessoas soronegativas que mantêm contato sexual com pessoas HIV positivas. Eles prepararam um questionário - um "teste de compreensão" - sobre o objetivo do estudo, a participação voluntária, os riscos e benefícios e o conhecimento sobre prevenção do HIV. No modelo "padrão", o médico-pesquisador conduziu o processo de consentimento em uma sessão, comunicando os elementos-chave aos participantes da pesquisa e incentivando-os a fazer perguntas. Nesse caso, apenas 20\% dos participantes passaram no "teste de compreensão".

No segundo modelo, um assistente social conduziu o processo de consentimento em três sessões - cada uma de 30 a 40 minutos - durante um período de sete a dez dias. O assistente social dividiu o TCLE em mensagenschave comunicadas verbalmente e também utilizou recursos visuais (imagens e modelos anatômicos). Nesse caso, $80 \%$ passaram no teste de compreensão e $12 \%$ recusaram-se a fazê-lo durante as reuniões. Mais de um terço dos participantes da pesquisa em ambos os coortes eram analfabetos. O que esse tipo de estudo mostra é que os participantes podem compreender informações complexas se houver estratégia suficiente. Nesse sentido, o analfabetismo por si só não é um obstáculo tão grande.

$\mathrm{O}$ "consentimento da comunidade" deve ser colocado em perspectiva. É evidente que, em culturas de base comunitária, a comunidade deve ser envolvida no processo, que pode haver a necessidade de um assentimento da comunidade, e que esta pode funcionar como um "filtro". Mas isso não deve ser equivalente a "apagar" o participante da pesquisa. Cada sujeito "coloca" seu corpo na pesquisa. Eles devem ser respeitados. Eles têm valores e a possibilidade de compreensão e de escolha, mesmo que se aceite e se respeite que a implementação desse processo pode ser influenciada e modificada por sua cultura. Por mais importância que o envolvimento da comunidade possa ter, seu consentimento não pode substituir o da pessoa. E isso é vital quando se trata de pesquisa biomédica ou quando há riscos para os participantes do estudo.

$\mathrm{Na}$ prática, o respeito pelo indivíduo e pela comunidade pode implicar algumas questões: por exemplo, um prazo maior que deve ser levado em conta durante o delineamento do ensaio e a decisão sobre quem realmente "representa" a comunidade. O mesmo se aplica à participação da "família" - o que normalmente indica membros do sexo masculino. Envolver o parceiro não significa substituir a mulher. Portanto, devem-se tomar cuidados especiais. Por exemplo, a proteção da confidencialidade e da privacidade da mulher deve ser incorporada na elaboração do procedimento de consentimento. Hyder e Wali não apóiam um ponto de vista em particular sobre o assunto; contudo, citam um entrevistado que está bem ciente dos desafios envolvidos (2006: 38):

\footnotetext{
Pode ser apropriado ou suficiente assegurar que líderes comunitários sejam informados do estudo em vez de exigir sua aprovação. Em comunidades em que a liderança poderia estar vinculada a políticas predominantes e/ou tendenciosas em favor dos homens, tal exigência pode não cumprir os objetivos éticos como previsto.
} 
O segundo ponto que Hyder e Wali apresentam diz respeito à questão da flexibilidade, crítica que tem sido feita repetidamente. Por exemplo, Onora O'Neill (2006), ao lidar com pesquisas em geral, diz que os "procedimentos de consentimento são freqüentemente mais formais do que genuínos, porque muitas interações para obtenção do TCLE apresentam-se comumente inadequadas epistemologicamente. Portanto, também há razões para refletir sobre as práticas utilizadas para solicitar o TCLE”.

No entanto, documentos éticos, tais como as Diretrizes do CIOMS/OMS (2002), explicitamente levam em conta a flexibilidade caso haja aprovação do comitê de ética. Parte do problema relacionado à falta de flexibilidade é a abordagem legalista de certas culturas, tais como a estadunidense, a falta de instrução dos pesquisadores ou dos comitês de ética em pesquisa no país do patrocinador, ou ainda a pressão das empresas farmacêuticas. Entretanto, flexibilidade não é sinônimo de "qualquer coisa é permitida". Ela deve implicar um procedimento equivalente por meio do qual o sujeito compreenda os objetivos da pesquisa, o delineamento e a relação risco-benefício, e possa escolher se deseja participar ou não. Para atingir esse objetivo, os investigadores devem conceber a elaboração do TCLE dentro de um contexto, e não como a mera tradução de formulários. Idealmente, pesquisadores locais devem estar envolvidos desde o início.

Há uma série de estratégias bem elaboradas e inovadoras que podem ser aplicadas para levar a flexibilidade em consideração e ainda tornar possível obter e medir a compreensão. Algumas delas foram publicadas no relatório de um workshop internacional (Mc Grory et al. 2006). Por exemplo, utilizaram-se instrumentos tais como folhetos, panfletos, quadros demonstrativos, anúncios em rádio ou jornal, vídeos, auto-instrução em áudio via computador e painéis flip charts. Em se tratando de ensaios de prevenção do HIV, usaram-se também alguns outros recursos visuais, como frascos de sangue, espéculos, caixas de produtos e envelopes de randomização para ilustrar determinados procedimentos do ensaio (Mc Grory et al. 2006). Algumas dessas estratégias são bastante onerosas, mas se justificam quando a pesquisa apresenta desafios específicos e mais do que riscos mínimos.

No entanto, um estudo realizado por Flory e Emanuel (2004) concluiu que a utilização de multimídia e de formulários aprimorados de consentimento tem tido sucesso limitado. Em vez disso, fazer com que um membro da equipe de pesquisa ou um educador neutro gaste mais tempo conversando com os participantes do estudo, um por um, parece ser o modo mais eficaz disponível de melhorar a compreensão dos sujeitos. Os autores reconhecem que é preciso realizar mais pesquisas, mas essa estratégia aparentemente simples e de "senso comum" soa bastante promissora.

Finalmente, Hyder e Wali reconhecem que a vasta maioria dos pesquisadores busca um mecanismo para medir a compreensão. Esse último ponto parece reforçar a importância de atingir as condições epistemológicas do
TCLE. De certa forma, ele salienta parte do que as duas primeiras críticas sugeriram: a importância de um bom processo de consentimento, que garanta a compreensão. Como mencionado, há várias inovações e mecanismos a serem incorporados a fim de assegurar que a condição epistemológica seja alcançada e que a compreensão durante o processo de consentimento seja efetivamente atingida.

\section{Condições contextuais e consentimento livre e esclarecido}

Outra questão a ser destacada sobre o TCLE está relacionada à descrição que os autores de Consentimento livre e esclarecido em pesquisa internacional: perspectivas da Índia, do Irã e da Nigéria apresentam. Em relação à Índia, eles afirmam:

O sistema de saúde pública é precário em termos de infra-estrutura e pessoal, bem como de medicamentos. Isso afeta negativamente o padrão de cuidado que está disponível publicamente [...]. Embora a maior parte dos comitês de ética esteja localizada dentro de instituições acadêmicas, nos últimos anos, muitos comitês de ética comerciais pró-lucro foram também formados na Índia, paralelamente ao fenômeno do aumento da terceirização dos ensaios clínicos para o país. (Bhan et al. 2006: 37).

Em maior ou menor escala, essas descrições revelam algo bastante comum em países em desenvolvimento: infra-estrutura pública insuficiente e privatização dos cuidados de saúde e da pesquisa. Mesmo que os autores do referido artigo não se aprofundem nesse problema, esse quadro mostra uma das principais questões relativas ao TCLE: as condições contextuais em que ele é obtido.

Ainda nesse sentido, um artigo que apresenta os limites do TCLE nas Filipinas afirma que algumas conjunturas, tais como pobreza, marginalização e extrema necessidade, bem como a comercialização de medicamentos, tornam participantes pobres de ensaios clínicos virtualmente incapazes de exercer livremente o princípio do consentimento voluntário (Alvarez Castillo 2002). E acrescenta: "O consentimento em participar de um ensaio clínico, quando analisado nesse contexto, perde o seu valor como um instrumento de proteção aos participantes de pesquisa" (Alvarez Castillo 2002: 25).

Ao retornar à distinção entre problemas epistemológicos e de ação, pode-se verificar que as objeções levantadas anteriormente foram fundamentalmente epistemológicas. No entanto, os problemas aqui apresentados são de natureza diferente. Eles apontam para as condições contextuais em que o consentimento é dado, para a possibilidade de exercer livremente o princípio do consentimento voluntário em primeira pessoa.

Perante esse cenário contextual, deve-se questionar seriamente o quão "voluntário" o TCLE realmente é quando o sistema público de saúde é inadequado. Por exemplo, analisando a qualidade do consentimento dos pais em um estudo sobre malária, na Uganda, os autores salientam que muitos deles sentiam que não poderiam ter se recusado a participar porque seus filhos estavam 
doentes, e eles ou não sabiam ou não acreditavam que seus filhos iriam receber tratamento fora do estudo (Pace et al. 2005).

O TCLE prevê a possibilidade de rejeitar a participação na pesquisa. Mas essa é de fato uma opção quando não há outras alternativas ou quando as alternativas existentes implicam ou a participação na pesquisa ou a doença e a morte? Note-se que, no estudo de Pace et al. (2005), a expectativa de benefícios à saúde é uma razão principal para participar. Adicione-se a isso a possibilidade de confusão entre pesquisa e tratamento. ${ }^{6}$ Esses são problemas graves quando o único "cuidado de saúde" disponível é a pesquisa. Em muitos países em desenvolvimento, é bastante evidente que a única oportunidade de obter pelo menos alguns cuidados de saúde é por meio da participação no experimento e que, o que quer que seja oferecido, constituirá uma escolha racional. Mas isso não significa que aquilo será justo; pode até mesmo ser exploratório (Macklin 2004; Luna 2007). ${ }^{7}$

Essas últimas questões com relação ao contexto de escassez de recursos e desespero são "o desafio" do TCLE em países em desenvolvimento. Embora não haja evidência clara de coerção, podemos falar de "quase-coerção" (Rivera López 2003). Esse conceito reconhece as dificuldades de certos contextos, em que os indivíduos têm de escolher entre alternativas que não são as melhores. Nessas situações, a escolha não é coagida, pois os indivíduos não são literalmente forçados a optar por uma alternativa entre as outras, mas suas decisões não podem ser consideradas totalmente voluntárias. Quando não há nenhuma alternativa razoável, aceitar uma opção onerosa, como participar da pesquisa, não pode ser considerado uma escolha livre, pois não tê-la escolhido significaria um dano ou ônus maior para o indivíduo.

Isso significa que o TCLE é "inútil” nos países em desenvolvimento? $\mathrm{O}$ artigo filipino ou o conceito de "quase-coerção" alertam sobre a perda de valor do TCLE (Alvarez Castillo 2002). Contrariamente a essa perspectiva, o TCLE é útil e valioso, mas, para que o seja de fato, há de se cumprir determinadas pré-condições. A proteção é uma questão importante. Outras são evitar a exploração e proporcionar uma relação risco-benefício adequada. Só então o TCLE fará sentido.

\section{A base teórica}

Neste ponto, é interessante analisar a base teórica do TCLE. A justificativa teórica tradicional do TCLE é o princípio do respeito pelas pessoas. Um dos primeiros e principais documentos que fornecem uma justificativa ética é o Relatório Belmont (United States of America 1979). Esse documento, elaborado pela Comissão Nacional para a Proteção de Participantes Humanos de Pesquisa Biomédica e Comportamental, desenvolveu três princípios éticos fundamentais que devem reger a pesquisa com seres humanos.

Os três princípios éticos fundamentais do documento são: a) respeito pelas pessoas; b) beneficência; e c) justiça. Este artigo irá centrar-se no princípio do respeito pelas pessoas, porque é o que está diretamente relacionado ao TCLE. Esse princípio incorpora pelo menos duas convicções éticas: em primeiro lugar, que os indivíduos devem ser tratados como agentes autônomos; em segundo lugar, que as pessoas com capacidade reduzida devem ter direito a proteção. Portanto, esse documento afirma:

Uma pessoa autônoma é um indivíduo capaz de deliberar sobre seus objetivos pessoais e de agir em direção a tal deliberação. Respeitar a autonomia é valorizar as opiniões e escolhas das pessoas autônomas, evitando, dessa maneira, obstruir suas ações, a menos que sejam claramente prejudiciais a outrem. (United States of America 1979, Section B).

Mas o Relatório Belmont também observa que nem todo ser humano é capaz de se autodeterminar: “[...] Algumas pessoas perdem essa capacidade total ou parcialmente devido a doenças, distúrbios mentais ou circunstâncias que restrinjam severamente a liberdade. $\mathrm{O}$ respeito pelos imaturos e incapacitados pode requerer protegê-los à medida que amadurecem ou enquanto estiverem incapazes" (United States of America 1979, Section B). Esse segundo aspecto do princípio do respeito pelas pessoas é muito importante, porque reconhece não apenas a autonomia, mas também a necessidade de proteção quando essa autonomia não funciona parcial ou totalmente.

Outro problema que esse documento considerou foi a inclusão voluntária em pesquisa. Ele tomou como exemplo a participação de prisioneiros em experimentos. Com relação a esse assunto, afirmou-se:

Por um lado, parece que o princípio do respeito pelas pessoas exige que os prisioneiros não sejam privados da possibilidade de se candidatar como voluntários à pesquisa. Por outro lado, sob condições de encarceramento, eles podem ser sutilmente coagidos ou indevidamente influenciados a participar de atividades de pesquisa às quais eles não se candidatariam em outros contextos. $\mathrm{O}$ respeito pelas pessoas determina, dessa forma, que os prisioneiros sejam protegidos. (United States of America 1979, Section B).

Nesse mesmo documento, o consentimento livre e esclarecido é analisado como contendo três elementos: informação, compreensão e voluntariedade. Ao falar de informação, o relatório enumera alguns itens a serem informados, os quais são estabelecidos pela maioria dos códigos de pesquisa (United States of America 1979, Section C). O ponto dedicado à compreensão afirma que a forma e o contexto em que a informação é transmitida são tão importantes quanto a informação em si. Ele também esclarece que, como a capacidade de compreensão do indivíduo é uma função da inteligência, racionalidade, maturidade e linguagem, é necessário adaptar a apresentação das informações às habilidades do indivíduo. Note-se que esses dois primeiros elementos são a análise teórica da condição epistemológica apresentada neste artigo.

No que diz respeito ao último ponto, voluntariedade, o Relatório Belmont ressalta que esse elemento requer que as condições para o consentimento sejam livres de coação e de influência indevida. E afirma: 
A coerção ocorre quando uma ameaça evidente de dano é feita intencionalmente por alguém a outrem para obter complacência. A influência indevida, pelo contrário, surge quando há oferta de uma recompensa excessiva, injustificada, inadequada ou imprópria, ou outra proposta para se obter complacência. Além disso, incentivos que normalmente seriam aceitáveis podem tornar-se influências indevidas se o sujeito for especialmente vulnerável. (United States of America 1979, Section C).

Ao analisar casos de pressões injustificáveis, o documento afirma que isso normalmente ocorre "quando pessoas em posição de autoridade ou de comando - especialmente se há possíveis sanções envolvidas - impõem um curso de ação a um participante" (United States of America 1979, Section C).

Os tipos de exemplos considerados nesse documento são baseados nos casos mencionados na primeira parte deste artigo, bem como nas condições contextuais que motivaram a necessidade de uma séria reflexão sobre ética em pesquisa. Por exemplo, quando se fala de voluntariedade, o dilema é apresentado em função de prisioneiros, pessoas isoladas em instituições onde seus direitos podem ser ignorados. Ainda está presente não apenas o fantasma dos experimentos nazistas, mas também toda a pesquisa realizada na era de ouro envolvendo pessoas que viviam em instituições de saúde (idosos, órfãos ou crianças com deficiência mental). Deve-se considerar também que, mesmo quando a importância de proteger participantes de pesquisa é reconhecida, esse fator está diretamente ligado à capacidade de deliberação. A ênfase parece recair sobre a descrição das pessoas com a capacidade (ou seja, a condição epistemológica) reduzida como as que devem ter o direito à proteção.

Mas esse é apenas um caso; existem outras situações que não estavam suficientemente presentes naquele momento. O Relatório Belmont considera apenas superficialmente a situação dos incentivos para pessoas especialmente vulneráveis. E uma leitura rápida das bases teóricas do TCLE pode ignorar a necessidade de proteção adequada em certos casos que ultrapassam as situações epistemológicas e falam de voluntariedade - o terceiro elemento descrito pelo relatório.

\section{Pressupostos problemáticos}

Existe uma justificativa reducionista do TCLE que pode acarretar em determinada visão do participante da pesquisa, que por vezes é apresentado de maneira demasiado simplista e idealizada. Se o foco recai apenas no aspecto da autonomia, parece que a única característica importante é a capacidade de deliberação. Ou seja, responde-se apenas aos problemas epistemológicos. Note-se que respeitar a autonomia é valorizar as opiniões e escolhas das pessoas autônomas, evitando, dessa maneira, obstruir suas ações, a menos que sejam claramente prejudiciais a outrem. Caso se considere apenas o fator deliberativo, o processo de consentimento livre e esclarecido pode ser equiparado a um contrato, e o participante de pesquisa, ao contratante, ou seja, a um agente idealizado agindo no vácuo. Essa postura implica uma oferta de participar em determinada atividade, as informações sobre as opções e a livre escolha da pessoa em envolver-se naquela atividade, como se as opções e a capacidade de livre escolha não fossem problemáticas.

Mas o Relatório Belmont fala do princípio do respeito pelas pessoas. Isso implica não só autonomia, mas também proteção. No entanto, no relatório, essa proteção é exemplificada principalmente em relação à capacidade intelectual reduzida, isto é, a deficiências epistemológicas. Se for considerado apenas isso, haverá uma compreensão do princípio do respeito pelas pessoas que pode não levar em conta suficientemente o elemento voluntariedade que deveria estar envolvido. E mesmo se o Relatório Belmont chama a atenção para a voluntariedade, na maioria das vezes a leitura se resume aos aspectos ligados à coerção não-externa ou à recompensa excessiva, injustificada, inadequada ou imprópria a fim de se obter complacência. Freqüentemente, isso é interpretado como a idéia de evitar oferecer presentes ou pagamentos que possam interferir na voluntariedade. Ou, como no exemplo considerado no próprio relatório, como alterações na voluntariedade, dado que o TCLE pode ser solicitado por alguém em posição de autoridade que pode influenciar indevidamente a decisão. No entanto, há outras maneiras mais sutis de interferir no processo de consentimento que dizem respeito à voluntariedade e à capacidade de livre ação do indivíduo. Se o TCLE só se justifica pela necessidade de uma decisão autônoma, pode-se arriscar assumir uma visão demasiado simplista dos sujeitos de pesquisa.

Já existem discussões voltadas para a conceituação do participante de pesquisa (Luna 2007). Nesses debates, foram aprofundadas algumas idéias de Swazey e Glantz (1982, 1995). Esses autores oferecem uma análise interessante das obrigações da sociedade e das compensações aos participantes de pesquisa prejudicados. Eles não pensam especificamente no conceito de participante, mas sua análise poderia ser facilmente estendida até essa questão. Eles questionam se é permitido considerar participantes de pesquisa como heróis altruístas, benfeitores, contratantes voluntários ou vítimas. Observa-se que o tipo de modelo usado para pensar sobre o que é ser um sujeito de pesquisa afeta a forma como a sociedade deve tratar os participantes. Os dois modelos que podem ser tomados da proposta dos autores são aqueles em que os sujeitos de pesquisa são tidos como contratantes e/ou como vítimas. ${ }^{8}$

O modelo do contratante segue o padrão do empresário negociando: desde que o processo de negociação seja justo, os contratantes têm direito a não mais do que aquilo que negociaram. ${ }^{9}$ As vítimas, por outro lado, são aqueles que foram tratados injustamente ou prejudicados sem seu consentimento. Elas podem ser especialmente vulneráveis ou o alvo de comportamento exploratório e pouco podem fazer para evitar esses danos.

O modelo do contratante voluntário é aceitável? Parece que sim, no caso de sujeitos de pesquisa ingleses ou suecos, que têm acesso a um sistema de saúde universal. No entanto, mesmo nesses casos, é preciso considerar 
problemas como a confusão entre pesquisa e tratamento, bem como o estresse emocional causado pela quantidade de alternativas terapêuticas disponíveis. Pacientes com acesso aos tratamentos existentes estão em uma condição melhor que aqueles sem acesso. Eles podem testar a melhor terapia disponível ou participar de um ensaio, ponderar os riscos e benefícios e tomar uma decisão. Essa pode ser uma descrição precisa se não se levar em conta a gravidade de algumas doenças e o estresse a que o paciente possa estar submetido. Entretanto, considerar os participantes de pesquisa como meros contratantes parece demasiado simplista. Quando se concebe o TCLE como um contrato a ser negociado, está sendo adotada uma visão inadequada do participante de pesquisa.

O modelo de um mero contratante não funciona, ainda mais no caso de alguém que vive em situação de pobreza absoluta e/ou em um país pobre. Como os pacientes podem negociar quando seu único meio de acesso ao tratamento é um ensaio clínico? Note-se também que, quando se pensa na imagem do contratante, não se considera que esses não são contratos perfeitos. Eles ocorrem no mundo real e dependem do poder de negociação dos envolvidos. Onora O’Neill (1996) indica o quão importante a possibilidade de recusa ou renegociação é para verificar se o consentimento não é uma mera formalidade. Nesses casos, a real possibilidade de recusa é vital. Parece que se está deixando algo de lado quando o foco é apenas em ter um "contrato".

Será que se deve apoiar, então, a imagem da vítima? Em sua análise, Swazey e Glantz presumem que as vítimas são aquelas com total falta de consentimento (vítimas dos nazistas ou do experimento Tuskegee). Esses casos são modelos claramente antiéticos e não podem ser justificados. É evidente que houve alguma forma de coerção neles, e talvez as vítimas tenham direito a compensação (Swazey \& Glantz 1995). ${ }^{10}$ Contudo, não se deve centrar em tais casos extremos, que são obviamente antiéticos. Como já mencionado, há outras situações em que se podem encontrar "vítimas". Pessoas vulneráveis ou com recursos escassos são passíveis de serem vítimas, mas não foram de fato prejudicadas ou coagidas. Assim, dano e coação exigem uma compensação justa, ao passo que a quase-coerção pode exigir outras medidas. Portanto, em vez de pensar em compensações, é necessário pensar em proteção adequada.

Dessa forma, deve-se considerar um modelo misto: aquele em que o papel do sujeito de pesquisa como um contratante é respeitado, mas em que a possibilidade de ele ser uma vítima também é levada em conta. O conceito de um participante de pesquisa deve refletir as duas imagens. Existem os aspectos de um contratante voluntário - daí a importância do consentimento livre e esclarecido -, mas há também, em muitos casos, a possibilidade de a pessoa apresentar as características de uma vítima - daí a importância de uma proteção adequada. Nesse sentido, em cada situação de pesquisa, o modelo prevalecente deve ser avaliado: se o indivíduo é um contratante voluntário ou uma vítima; ou o quanto de um contratante e o quanto de uma vítima estão presentes.
Essa avaliação irá ajudar a estabelecer as medidas de segurança e proteções adequadas.

Não se deve esquecer de outros fatores "sutis" que parecem ser determinantes - por exemplo, a vulnerabilidade. A ética em pesquisa não pode evitar esse fator. Nesse sentido, as condições em que o TCLE é dado são fundamentais: deve ficar claro que o TCLE é verdadeiramente voluntário, e não a conseqüência da indisponibilidade de outras opções. Mas essas últimas questões estão relacionadas a novas situações, em que ocorrem pesquisas multicêntricas. Não estão sendo enfrentados os problemas de pesquisa da era de ouro, mas sim aqueles de um mundo globalizado: por exemplo, o desafio de replicar na Argentina, na Bolívia, no Brasil, na Tailândia ou na Uganda um protocolo que foi concebido em Johns Hopkins ou Paris. Esses são países com situações socioeconômicas muito diversas, onde o contexto em que o TCLE é dado merece atenção. A justificativa teórica do TCLE tem que considerar esses outros aspectos, que foram sugeridos no Relatório Belmont, mas não suficientemente enfatizados. $\mathrm{O}$ aspecto deliberativo do TCLE é coberto pelo fator autonomia do princípio do respeito pelas pessoas, mas a voluntariedade e a capacidade de ação do sujeito de pesquisa não podem ser esquecidas.

Os dois níveis de problemas apontados neste artigo, o epistemológico e os relativos à ação, são claramente ilustrados em uma visão não-reducionista da justificativa do TCLE, bem como do sujeito de pesquisa. Dessa forma, nessa visão não-reducionista, o modelo misto de conceituação de um sujeito de pesquisa permite compreender e dar uma resposta aos dois níveis de problemas que o TCLE em países em desenvolvimento apresenta hoje.

\section{Conclusão}

Neste artigo, foi apresentado como o TCLE se desenvolveu e foi associado a casos clássicos de ética em pesquisa. Acredita-se que esses primeiros casos também moldaram as bases teóricas do TCLE e que uma rápida leitura do Relatório Belmont pode não considerar o elemento voluntário em relação a fatores sutis, como o contexto de escassez de recursos. Este último é atualmente um problema inevitável na pesquisa em países em desenvolvimento.

Mostrou-se que problemas epistemológicos não são obstáculos intransponíveis. O analfabetismo pode ser superado, e o processo de consentimento deve continuar sendo melhorado. Além disso, métodos sofisticados podem não ser necessários; o mecanismo de senso comum e "baixa tecnologia" de passar mais tempo conversando um a um com os participantes do estudo parece promissor. A flexibilidade pode ser incorporada à proteção adequada e cuidadosa dos sujeitos de pesquisa, bem como a mecanismos para medir a compreensão.

Em relação à voluntariedade e à ação, o mínimo a se fazer, a fim de conduzir pesquisas éticas em países em desenvolvimento, é considerar o contexto e as condições de escassez de recursos em que a pesquisa é proposta, de modo a fornecer mecanismos de proteção adequados. Nesse sentido, uma relação apropriada de risco-benefí- 
cio - uma que não colocará os indivíduos em risco e na qual os mecanismos de proteção se encontram ativos - é fundamental. Entre outras medidas de segurança, é vital considerar os comitês de ética em pesquisa, em particular os comitês locais. Eles têm uma grande responsabilidade na revisão dos protocolos, e devem ser fortes e independentes o bastante para aceitar livremente as propostas de pesquisa, solicitar mudanças nas mesmas, ou rejeitá-las.

A escassez de recursos é um grande problema. É um convite à exploração, porém, não é um desafio apenas para o TCLE em países em desenvolvimento, mas para a pesquisa em países em desenvolvimento de um modo geral. No entanto, isso não quer dizer que se deva interromper a pesquisa nesses países. Ela é de crucial importância para eles. Mas deve haver uma clara percepção dos desafios e problemas envolvidos. Por exemplo, quais são as obrigações durante e após a pesquisa; o quão relevante é a investigação para aquela população; e se os frutos do experimento serão colocados à disposição da comunidade. O TCLE é muito importante na pesquisa; é uma condição necessária, mas não suficiente. Acima de tudo, é fundamental evitar a exploração e tratar os sujeitos de pesquisa respeitosamente. Somente então um processo de consentimento cuidadoso e sensível ao contexto poderá ser uma ferramenta útil para os países em desenvolvimento.

\section{Notas}

1. Ao contrário do que se alegou em uma justificação pós-guerra, os médicos nunca foram forçados a conduzir esses experimentos. Eles eram voluntários, e, em alguns casos, oficiais nazistas tiveram de impedir os médicos entusiasmados de levar adiante experimentos ainda mais ambiciosos.

2. Beecher (1966) relatou que, dos cinqüenta protocolos originais, apenas dois mencionaram ter obtido o consentimento, mas limitaram-se a isso.

3. Baruch Brody (1998) exemplifica o mesmo ponto e adiciona dados de outras fontes. Por exemplo, ele diz que M. H. Pappworth publicou Human guinea pigs, no qual alegou problemas parecidos na pesquisa inglesa. No Canadá, muita atenção foi dada, na década de 1960, ao caso Halushka, em que um participante que não tinha recebido informações adequadas sobre o estudo sofreu sérios danos depois de utilizar um novo fármaco e de ser submetido a monitoramento invasivo. Na Nova Zelândia, as investigações nos anos 1980 focavam as pesquisas dos anos 1960 e 1970, nas quais mulheres com câncer cervical in situ deixavam de ser tratadas a fim de que se pudesse estudar a história natural da doença. Como esperado, muitas desenvolveram carcinoma invasivo, o qual levou algumas a óbito.

4. Essa é uma referência à Nigéria.

5. Pace C; Grady C; Emanuel E. The quality of informed consent for clinical research: a comparative review of empirical data from developing and developed countries. Artigo preliminar. Foi obtida a permissão de Emanuel para os comentários.
6. Esse problema não será aprofundado neste artigo.

7. Esse tópico tem sido explorado apenas recentemente.

8. As duas outras imagens, do herói altruísta e do benfeitor, não serão levadas em consideração. Heróis agem voluntariamente e assumem riscos em benefício de outrem. Uma vez que os heróis não esperam recompensa, a sociedade não tem obrigação alguma de compensar sujeitos de pesquisa heróicos. Algo semelhante ocorre com os benfeitores. Embora tais doadores possam não ter direito moral a compensação, a sociedade pode querer retribuir o favor, compensando-lhes os prejuízos.

9. A concepção de justiça envolvida nessa idéia é puramente formal ou processual. Segue um modelo libertário de justiça, como propõe, por exemplo, Robert Nozick.

10. Vítimas têm uma forte exigência moral quanto à compensação, especialmente nas áreas onde a sociedade facilitou a pesquisa ou se beneficiou dela.

\section{Referências bibliográficas}

Alvarez Castillo F. Limiting factors impacting on voluntary first person informed consent in the Philippines. Developing World Bioethics. 2002; 2(1):21-7.

Annas GJ, Grodin MA. The nazi doctors and the Nuremberg Code. Oxford: Oxford University Press; 1992.

Beecher H. Ethics and clinical research. New England J Med. 1966; 274(24): 1354-0.

Bhan A, Majd M, Adejumo A. Informed consent in international research: perspectives from India, Iran and Nigeria. Medical Ethics. 2006; 3(1):36-41.

Brody B. The ethics of biomedical research. Oxford: Oxford University Press; 1998.

CIOMS/WHO. International ethical guidelines for biomedical research involving human subjects. Geneve: CIOMS/OMS, 2002. Disponível em: <http://www.cioms.ch/frame guidelines nov 2002.htm >. Acesso em: 1 mar. 2007.

Fitzgerald D, Pape J, Wasserheit J et al. Provision of treatment in HIV-1 vaccine trials in developing countries. The Lancet. 2003; 362(9388):993-4.

Flory J, Emanuel E. Interventions to improve research participants' understanding in informed consent for research. JAMA. 2004; 392(13): 1593-1602.

Heise L, Wood S. Rethinking the ethical roadmap for clinical testing of microbicides: report on an international consultation (October, 2003). Washington, D.C.: Global Campaign for Microbicides; 2005.

Hyder A, Wali S. Informed consent and collaborative research: perspectives from the developing world. Developing World Bioethics. 2006; 6(1):33-0.

Levine C. Placebos and HIV: lessons learned. Hastings Center Report. 1998; 28:43-4. 
Luna F. Bioethics and vulnerability: a Latin American view. New York/Amsterdam: Rodopi; 2006.

Luna F. Research in developing countries. In: Steinbock B. The Oxford handbook of bioethics. Oxford: Oxford University Press; 2007. p. 621-47.

Macklin R. Double standards in medical research in developing countries. Cambridge: Cambridge University Press; 2004

Mc Grory E, Friedland B, Woodsong C et al. Informed consent in HIV prevention trials: report on an international workshop. New York: Population Council; 2006.

Nuremberg Military Tribunals. The Nuremberg Code. Washington, D.C.: Government Printing Office, 1947. Disponível em: <http://ohsr.od.nih.gov/guidelines/ nuremberg.html>. Acesso em: 1 mar. 2007.

O’Neill, O. Justicia, sexo y fronteras internacionales. In: Nussbaum M, Sen A, editores. La calidad de vida. Mexico: Fondo de Cultura Económica; 1996. p. 393-417.

O’Neill, O. Nuremberg to Helsinki: rising or falling standards in research on human subjects? In: World Congress of Bioethics, Aug 8, 2006, Beijing, China.

Pace C, Grady C, Emanuel E. What we don't know about informed consent. Disponível em: <http://www.scidev. net/en/opinions/what-we-dont-know-about-informedconsent.html>. Acesso em: 1 mar. 2007.

Pace C, Talisuna A, Wendler D et al. Quality of parental consent in a Ugandan malaria study. Am J Public Health. 2005; 95(7):1184-0.

Resnik DB. The ethics of HIV research in developing nations. Bioethics. 2002; 12:286-306
Rivera López E. Ética y trasplantes de órganos. México: UNAM/Fondo de Cultura Económica; 2003.

Rothman D. Strangers at the Bedside: a history of how law and bioethics transformed medical decision making. United States: Basic Books; 1991.

Swazey JP, Glantz L. A social perspective on compensation for injured research subjects. In: President's Commission for the Study of Ethical Problems in Medicine and Biomedical and Behavioral Research. Compensating for research injuries. United States: Federal Register, 1982; 2: 3-18.

Swazey JP, Glantz L. A social perspective on compensation for injured research subjects. In: Mariner W. Adverse reactions to HIV vaccines: medicine, ethical and legal issues. Washington, D.C.: Congress of the United States; 1995.

United States of America. Department of Health, Education, and Welfare. The National Commission for the Protection of Human Subjects of Biomedical and Behavioral Research. The Belmont report: ethical principles and guidelines for the protection of human subjects of research. Washington, D.C.: US Government Printing Office; 1979.

Vargas-Parada L, Kawa S, Salazar A et al. Informed consent in clinical research at a general hospital in Mexico: opinions of the investigators. Developing World Bioethics. 2006; 6(1): 41-51.

World Medical Organization. Declaration of Helsinki. British Med J. 1996; 313(7070):1448-9.

\section{Sobre o autor}

\section{Florencia Luna}

Florencia Luna é Pesquisadora Independente do CONICET (Conselho Nacional de Pesquisa Científica e Tecnológica), Argentina. É Diretora do Programa de Bioética, FLACSO (Universidade Latinoamericana de Ciências Sociais). É Diretora com Ruth Macklin (Co-Diretora) do fundo para o treinamento em pesquisa do Centro Internacional Fogarty, NHI (US). Presidente da Associação Internacional de Bioética (IAB) durante 2003 a 2005 . É autora de Bioethics and Vulnerability: a Latin American View (RODOPY, Amsterdam-US, 2006), e Ensayos de bioética: reflexiones desde el Sur (Fontamara, México, 2001). É co-autora de Decisiones de vida y muerte (Sudamericana, Buenos Aires, 1995) and Bioética (Sudamericana, Buenos Aires, 1998) e Bioética: nuevas reflexiones sobre debates clásicos (Fondo de Cultura Económica, 2008). Ela é assessora temporária da WHO (World Health Organization), da CIOMS-WHO Ethical Guidelines (2002) e Guggenheim Foundation Fellow (2006). 